\title{
Augmentation of chloramphenicol degradation by Geobacter-based biocatalysis and electric field
}

\author{
Leilei Xiao $^{\text {a,b }}$, Jiajia Li ${ }^{\text {a,b }}$, Eric Lichtfouse ${ }^{\mathrm{d}, \mathrm{e}, 1}$, Zhenkai Li ${ }^{\mathrm{f}}$, Quan Wang ${ }^{\mathrm{f}}$, Fanghua Liu ${ }^{\mathrm{a}, \mathrm{b}, \mathrm{c}, *}$ \\ ${ }^{a}$ Key Laboratory of Coastal Biology and Biological Resources Utilization, Yantai Institute of Coastal Zone Research, Chinese Academy of Sciences, Yantai 264003, PR \\ China \\ ${ }^{\mathrm{b}}$ CAS Key Laboratory of Coastal Environmental Processes and Ecological Remediation, Yantai Institute of Coastal Zone Research, Chinese Academy of Sciences, Yantai \\ 264003, PR China \\ ${ }^{\mathrm{c}}$ National-Regional Joint Engineering Research Center for Soil Pollution Control and Remediation in South China, Guangdong Key Laboratory of Integrated Agro- \\ environmental Pollution Control and Management, Institute of Eco-environmental and Soil Science, Guangdong Academy of Science, Guangzhou 510650, PR China \\ d Aix-Marseille Univ, CNRS, IRD, INRAE, Coll France, CEREGE, Avenue Louis Philibert, Aix en Provence 13100, France \\ e State Key Laboratory of Multiphase Flow in Power Engineering, Xi'an Jiaotong University, Xi'an, Shaanxi 710049, PR China \\ ${ }^{\mathrm{f}}$ School of Resources and Environmental Engineering, Ludong University, Yantai 264025, PR China
}

\section{A R T I C L E I N F O}

Editor: Dr. Rinklebe Jörg

\section{Keywords:}

Chloramphenicol removal

Geobacter

Electric filed

Critical voltage

Synergistic operation

\begin{abstract}
A B S T R A C T
Electroactive microorganisms and electrochemical technologies have been separately used for environmental remediation such as antibiotics removal, yet the efficiency of coupling these two methods for chlorinated antibiotics removal is poorly known. Here we tested the synergy of Geobacter sulfurreducens PCA, an electroactive bacteria, and an electrical field, on chloramphenicol removal. Removal is increased two-fold by increasing the temperature from $30^{\circ} \mathrm{C}$ to $37^{\circ} \mathrm{C}$. The cyclic voltammograms and chronoamperometry tests demonstrated that G. sulfurreducens PCA catalyzed chloramphenicol chemical reduction with electrode as excusive electron donor. A critical voltage, -0.6 to $-0.5 \mathrm{~V}$ vs. $\mathrm{Ag} / \mathrm{AgCl}$, was discovered for chloramphenicol degradation with an increase of removal rate about 2.62 -folds, from $31.06 \%$ to $81.41 \%$. Combined removal with both G. sulfurreducens PCA and an electrical field increased the apparent rate constant and reached $82.77 \%$ removal at $-0.5 \mathrm{~V}$. Specially, the combined removal at $-0.5 \mathrm{~V}$ even presented more robust removal efficiency compared to $-0.6 \mathrm{~V}(78.64 \%)$ without G. sulfurreducens PCA. Mass spectrometry of degradation products indicates the reduction of nitro into amine groups, and dechlorination into less toxic compounds. Overall, combined biocatalysis and an electrical field is a promising method to remove antibiotics from polluted environments.
\end{abstract}

\section{Introduction}

Antibiotics have been frequently detected in soil, surface water, groundwater and anaerobic engineering systems (Huang et al., 2019; Pan and Chu, 2016; Xiao et al., 2021; Yin et al., 2018). The extensive use of antibiotics poses a threat to the environment and human health by inducing the emergence of antibiotic resistant bacteria and genes (Aydin et al., 2015; Biancullo et al., 2019; Li et al., 2020). Chloramphenicol is a broad spectrum antibiotic intensively used in clinical practice, it is as an effective bacteriostatic antimicrobial for diverse bacteria (Liang et al., 2013; Zhang et al., 2020). The intensive use of chloramphenicol is of increasing concern due to its mutagenic, carcinogenic and toxic effects, notably for hematopoietic and digestive system in humans and animals
(Deng et al., 2017; Yang et al., 2020a). Nonetheless, chloramphenicol is still widely used in many developed countries due to its low manufacturing cost and extensive availability (Boeckx and Brett; 2019).

Chloramphenicol and some other antibiotic removal have been tested using physicochemical approaches such as adsorption (Zhao et al., 2016), advanced oxidation (Karaolia et al., 2018; Wang and Zhuan, 2020), nanoparticles treatment (Guo et al., 2019; Xu et al., 2020), UV/chlorine treatment (Dong et al., 2017), photocatalysis (Dou et al., 2020; Wei et al., 2020) and electrochemical oxidation/reduction (Garcia-Segura et al., 2014). Yet, these technologies are limited by high energy needs, chemical cost or secondary pollution. Alternatively, microbial degradation of chlorinated compound appears as a more sustainable method for chloramphenicol removal because some

\footnotetext{
* Correspondence to: Yantai Institute of Coastal Zone Research, 17 Chunhui Road, Laishan District, Yantai, Shandong 264003, PR China.

E-mail address: fhliu@yic.ac.cn (F. Liu).

1 Orcid: 0000-0002-8535-8073
} 
microorganisms tolerate chlorinated contaminants and perform dechlorination, thus decreasing toxicity (Boyd et al., 1983; Zhao et al., 2015).

Electroactive bacteria (EAB) have been recently used for bioremediation (Aulenta et al., 2010; Chen et al., 2018; Palma et al., 2018). For instance, Geobacter spp. are electroactive bacteria that are able to degrade monoaromatic hydrocarbons and tetracycline hydrochloride (Kunapuli et al., 2010; Liu et al., 2017a; Zhang et al., 2013). Further revealed that Geobacter spp. are involved in the dehalogenation of polychlorinated biphenyls in anaerobic sediments. Biochar-assisted dechlorination of pentachlorophenol by Geobacter sulfurreducens (Yu et al., 2015), has suggested the benefit of adding a conductive material because biochar conductivity has been later shown to improve performances (Xiao et al., 2019a, 2020a). This is explained by the fact that Geobacter spp. grow well on electrodes by harvesting electricity from wastewater or sediments, due to their excellent ability of extracellular electron transfer (Wang et al., 2018; Yang et al., 2017). Therefore, both electromicrobiology and electrochemical technology appear promising for pollutant removal.

So far, either electroactive microorganisms or electric fields have been used separately for the removal of pollutants such as phenanthrene tetracycline hydrochloride (Peng et al., 2020; Sharma et al., 2020). Yet the feasibility, efficiency and mechanism of combining these two methods is poorly known, notably for chlorinated antibiotics. Here we studied: (1) the capability of Geobacter on chloramphenicol removal at diverse chloramphenicol concentrations and temperatures; (2) the reinforcing role of exogenous electric field for chloramphenicol removal; (3) a co-augmentation strategy, the combination of microbes and electric field, for chloramphenicol removal; and (4) the metabolic pathway of chloramphenicol at above co-augmentation strategy. This study proposes a promising strategy for removing antibiotics from wastewater.

\section{Materials and methods}

\subsection{Bacteria strain and growth conditions}

G. sulfurreducens PCA (ATCC 51573) was donated by Professor Lovley (Coppi et al., 2001), and was cultured with NBF medium containing $10 \mathrm{mM}$ acetate and $40 \mathrm{mM}$ fumarate as the electron donor and electron acceptor. Basic medium composition is $(\mathrm{g} / \mathrm{L}): \mathrm{CaCl}_{2} \cdot 2 \mathrm{H}_{2} \mathrm{O}$ 0.4, $\mathrm{MgSO}_{4} \cdot 7 \mathrm{H}_{2} \mathrm{O} \quad 0.1, \mathrm{NaHCO}_{3} \quad 1.8, \mathrm{Na}_{2} \mathrm{CO}_{3} \cdot \mathrm{H}_{2} \mathrm{O} \quad 0.5, \mathrm{Na}_{2} \mathrm{SeO}_{4} \quad 0.0002$, $\mathrm{K}_{2} \mathrm{HPO}_{4} 0.22, \mathrm{KH}_{2} \mathrm{PO}_{4} \cdot \mathrm{H}_{2} \mathrm{O} 0.42, \mathrm{NH}_{4} \mathrm{Cl} 0.2, \mathrm{NaCl} 0.36, \mathrm{KCl} 0.38$. The mineral and vitamin medium elements are: Free Acid Non-Trisodium Salt (NTA) 21.4, $\mathrm{MnCl}_{2} \cdot 4 \mathrm{H}_{2} \mathrm{O} 1, \mathrm{FeSO}_{4} \cdot 7 \mathrm{H}_{2} \mathrm{O} 3, \mathrm{CoCl}_{2} \cdot 6 \mathrm{H}_{2} \mathrm{O}$ 1.7, $\mathrm{ZnSO}_{4} \cdot 7 \mathrm{H}_{2} \mathrm{O} 2, \mathrm{CuCl}_{2} \cdot 2 \mathrm{H}_{2} \mathrm{O} 0.3, \mathrm{AlK}\left(\mathrm{SO}_{4}\right)_{2} \cdot 12 \mathrm{H}_{2} \mathrm{O} 0.05, \mathrm{H}_{3} \mathrm{BO}_{3} 0.05$, $\mathrm{Na}_{2} \mathrm{MnO}_{4} \cdot 2 \mathrm{H}_{2} \mathrm{O}$ 0.9, $\mathrm{NiSO}_{4} \cdot 6 \mathrm{H}_{2} \mathrm{O} 1.1, \mathrm{Na}_{2} \mathrm{WO}_{4} \cdot 2 \mathrm{H}_{2} \mathrm{O} 0.2$, biotin 0.03 , pantothenic acid 0.07, B-12 0.002, p-aminobenzoic acid 0.07, thioctic acid 0.07 , nicotinic Acid 0.07 , thiamine 0.07 , riboflavin 0.07 , pyridoxine $\mathrm{HCl} 0.15$, folic acid 0.03. All incubations and experiments were performed at $30^{\circ} \mathrm{C}$ in the dark under strict anaerobic conditions unless indicated otherwise.

\subsection{Removal of chloramphenicol by G. sulfurreducens PCA without electrical field}

Chloramphenicol removal was studied using the following procedure at two temperature: $25{ }^{\circ} \mathrm{C}$ (experiment 1 ) and $37{ }^{\circ} \mathrm{C}$ (experiment 2). Incubations were carried out in $100 \mathrm{~mL}$ serum bottles with $40 \mathrm{~mL}$ NBF medium using chloramphenicol ( $>98 \%$ purity) purchased from Aladdin (Shanghai, China). Bottles were sealed with thick butyl rubber and aluminium caps. About $5 \%(\mathrm{v} / \mathrm{v})$ of $G$. sulfurreducens PCA at stationary phase was added into serum bottles under the condition of nitrogensaturated atmosphere. Chloramphenicol was tested at 5, 10, 20, 30 and $50 \mathrm{mg} / \mathrm{L}$. Liquid samples were collected after 0, 24, 48, 72 and $96 \mathrm{~h}$ with a syringe in an anaerobic glovebox (Coy Laboratory Products), similarly as previous investigations (Li et al., 2018; Xiao et al., 2019b; Xiao et al., 2019c). All the incubation experiments were carried out in triplicate. After sampling, the samples were filtered through $0.22 \mu \mathrm{m}$ filters. Chloramphenicol concentrations were monitored using a 1260 Infinity high-performance liquid chromatography (HPLC) for Agilent Technologies, USA, equipped with a photodiode array detector. Analysis was performed using a $5 \mu \mathrm{m} ; 5 \times 250 \mathrm{~mm}$ C18 column from Agilent, eluting methanol/water $55 / 45$, v/v $1 \mathrm{~mL} / \mathrm{min}$ with ultraviolet detection at $275 \mathrm{~nm}$. Cell density was measured using a TU-1810 ultraviolet spectrophotometer at wavelength of $600 \mathrm{~nm}$.

\subsection{Analysis of chloramphenicol removal by electrochemistry}

Experiment 3: chloramphenicol removal were done by cyclic voltammetry and chronoamperometry in a three-electrode system using CHI660 electrochemical workstation form ChenHua, China, as Xiao et al. (2020b). A $3 \mathrm{~mm}$-diameter glassy carbon electrode, and a $1.5 \mathrm{~cm} \times$ $1.5 \mathrm{~cm}$ platinum sheet electrode served respectively as working electrode and auxiliary electrode. Reference electrode was $\mathrm{Ag} / \mathrm{AgCl}$ electrode. The working electrode was polished using successively $0.3 \mu \mathrm{m}$ and $0.05 \mu \mathrm{m}$ alumina slurries for $5 \mathrm{~min}$, rinsed with distilled water and ethanol 3 times, then dried in clean bench. The working electrode was then activated by cyclic voltammetry in a $0.1 \mathrm{M} \mathrm{H}_{2} \mathrm{SO}_{4}$ and examined in $10 \mathrm{mM}$ potassium ferricyanide until the peak potential difference was below $80 \mathrm{mV}$; sweep between $-1 \mathrm{~V}$ and $1 \mathrm{~V}$ at scan rate of $25 \mathrm{mV} / \mathrm{s}$.

G. sulfurreducens PCA solution of $0.5 \mathrm{OD}_{600}$ was harvested, $8000 \mathrm{rpm}$ centrifugated at $4{ }^{\circ} \mathrm{C}$ then and resuspended in $10 \mathrm{mM}$ phosphate buffer solution ( $\mathrm{PBS}, \mathrm{pH}=7$ ) for further analysis by cyclic voltammetry and chronoamperometry. Cyclic voltammetry was done in $30 \mathrm{~mL}$ oxygenfree PBS with centrifuged $G$. sulfurreducens PCA and $5 \mathrm{mg} / \mathrm{L}$ chloramphenicol. The voltage were between $-1 \mathrm{~V}$ and $1 \mathrm{~V}$ with a scanning rate of $10 \mathrm{mV} / \mathrm{s}$. PCA suspension was replaced with PBS solution in the control group. Chronoamperometry test was performed at a constant potential of $-0.6 \mathrm{~V}$ with and without $G$. sulfurreducens PCA of $0.5 \mathrm{OD}_{600}$. About $20 \mu \mathrm{L}$ chloramphenicol was added into the electrolyte every $100 \mathrm{~s}$ after the baseline reached steady state. All the experiments were conducted under strict anaerobic environment at $30^{\circ} \mathrm{C}$.

\subsection{Effect of electric field on chloramphenicol removal alone}

Experiment 4: The effect of electric field on chloramphenicol removal was carried out in a $100 \mathrm{~mL}$ single compartment electrolytic cell made of organic glass under galvanostatic conditions, after addition of $40 \mathrm{~mL}$ oxygen-free NBF medium containing $30 \mathrm{mg} / \mathrm{L}$ chloramphenicol. The electrolyte was acetate-free. Carbon cloths $(20 \times 20 \times 1 \mathrm{~mm})$ served as electrodes and were twisted by titanium wire of $0.8 \mathrm{~mm}$ diameter. Reference electrode was $\mathrm{Ag} / \mathrm{AgCl}$. Cathode potentials of -0.4 , $-0.5,-0.6$ and $-1.0 \mathrm{~V}$ vs. $\mathrm{Ag} / \mathrm{AgCl}$ were applied using a CHI660 electrochemical workstation. An open circuit experiment was used as the control. Solution was sampled at different time intervals then $0.22 \mu \mathrm{m}$ filtered. All operations were conducted under strict anaerobic condition at $30^{\circ} \mathrm{C}$.

\subsection{Synergistic effect of electric field and G. sulfurreducens PCA on chloramphenicol removal}

Experiment 5: The synergy of an electric field and G. sulfurreducens PCA for chloramphenicol removal was tested. That is, chloramphenicol removal may be promoted from the cooperation by biocatalysis from G. sulfurreducens PCA and physicochemical action from the electrode. In previous studies, a synergistic effect for antibiotic degradation occurred by coupling electrolysis with persulfate oxidation (Liu et al., 2018). Moreover, Liu et al. (2017b) proposed an effective tetracycline degradation attributed to the synergistic effects of direct and indirect electrochemical oxidation. Here, the synergistic action biocatalysis and electrochemistry was tested. $40 \mathrm{~mL}$ G. sulfurreducens PCA in the 
exponential phase was centrifuged at $8000 \mathrm{rpm}$ then washed with oxygen-free $10 \mathrm{mM}$ PBS at pH 7.0 three times. The collected cells were dissolved in $1 \mathrm{~mL}$ PBS and transferred into the electrolytic cell. The electrolyte was $40 \mathrm{~mL}$ oxygen-free sterile NBF medium with or without $10 \mathrm{mM}$ sodium acetate. The final concentration of chloramphenicol was $30 \mathrm{mg} / \mathrm{L}$ in the electrolyte. The applied cathode potential was -0.5 and $-0.6 \mathrm{~V}$ vs. $\mathrm{Ag} / \mathrm{AgCl}$, and other operations refer to experiment 4 . Experiments were conducted in the dark under strict anaerobic conditions at $30{ }^{\circ} \mathrm{C}$.

\subsection{Metabolic products analysis}

Experiment 6: chloramphenicol metabolites were studied by HPLCMS/MS (TSQ Quantum Access MAX, Thermo Fisher, USA) according to Schymanski et al. (2014). Three types of samples were tested in the end of experiment: 1 . A sample from experiment 4 at $-0.6 \mathrm{~V}$. 2 . A sample from experiment 5 at $-0.6 \mathrm{~V}$ with $G$. sulfurreducens PCA excluding sodium acetate. 3. A sample from experiment 5 at $-0.6 \mathrm{~V}$ with G. sulfurreducens PCA and sodium acetate. HPLC-MS/MS was set to positive ion mode. After cultivation, the samples were $0.45 \mu \mathrm{m}$ filtered then the supernatants were placed into a separatory funnel with equal volume of ethyl acetate with a 15-minute shock. The ethyl acetate layer was transferred to a rotary evaporation flask, evaporated to near dryness in a $45{ }^{\circ} \mathrm{C}$ water bath, dilute with $1 \mathrm{~mL}$ methanol and $0.22 \mu \mathrm{m}$ filtered prior measurement. The HPLC-MS/MS was equipped with an electrospray ionization source and operated in the positive/negative polarity mode. The column and detection conditions were consistent with the above HPLC detection method.

\subsection{Statistical analysis}

Data are presented as means \pm standard deviation of triplicate cultures. All statistical analyses were performed with the Origin 8.5 software from Origin Lab Corporation, USA. T-test was used to analyze the significance level, and a $p$ value below 0.05 was considered statistically significant.

\section{Results and discussion}

\subsection{Chloramphenicol removal dynamics by electroactive bacteria}

We tested the performance of $G$. sulfurreducens PCA for chloramphenicol removal at concentrations of $5,10,20,30,50 \mathrm{mg} / \mathrm{L}$ in experiment 1 at $30{ }^{\circ} \mathrm{C}$ (Fig. 1, Table 1). Results show that chloramphenicol removal within $96 \mathrm{~h}$ is $100 \%$ at $5 \mathrm{mg} / \mathrm{L}$ then decrease to $20 \%$ at $50 \mathrm{mg} / \mathrm{l}$. This removal can be attributed to microbial processes because our previous study showed that physico-chemical adsorption of chloramphenicol by Geobacter is negligible (Xu et al., 2019). Removal can be modelled by first order kinetics (Fig. 1b), as follows:

$\ln \left(\frac{C}{C_{0}}\right)=-k_{\text {app }} \mathrm{t}$

where $\mathrm{C}$ and $\mathrm{C}_{0}$ are chloramphenicol current and the initial concentrations, $k_{\text {app }}$ is the apparent rate constant, and t denotes time. $k_{\text {app }}$ at different chloramphenicol concentration was achieved through fitting curves (Table 1). Chloramphenicol removal dynamics provides comprehensive information such as the apparent rate constant $\left(k_{\mathrm{app}}\right)$, which measures the removal efficiency affected by single biological or electrochemical actions. Furthermore, $k_{\text {app }}$ is also a very important parameter to characterize the synergistic operation of biocatalysis and the electric field. Results show that $k_{\text {app }}$ values decrease from $0.0397 \mathrm{~h}^{-1}$ at $5 \mathrm{mg} / \mathrm{L}$ to $0.0043 \mathrm{~h}^{-1}$ at $50 \mathrm{mg} / \mathrm{L}$, in agreement with removal rates. This could be explained by chloramphenicol toxicity on $G$. sulfurreducen PCA, as suggested by previous reports showing the antibacterial effect on rate constants (Mao et al., 2018a; Pan and Chu, 2016). Therefore, we hypothesized that $G$. sulfurreducen PCA biomass decreased with increasing chloramphenicol concentration. This antibacterial effect is confirmed by biomass monitoring that shows that the optical density is sharply decreasing with chloramphenicol concentration, and that optical density is correlated with the removal rate (Fig. 1c, d). This is also supported by the fact that bioaugmentation should be done to improve bioremediation of antibiotics-contaminated soil by bioaugmentation (Cycon et al., 2019; Hong et al., 2020).
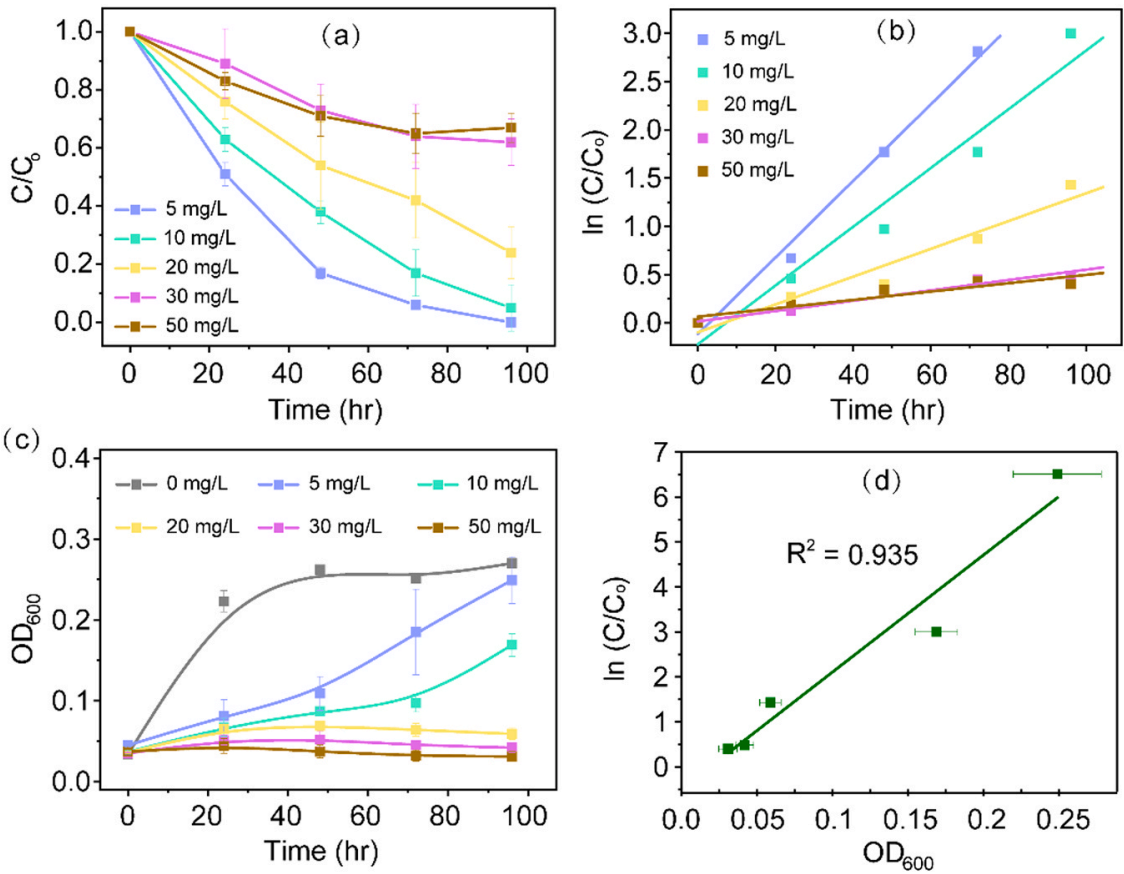

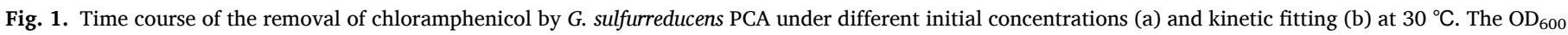

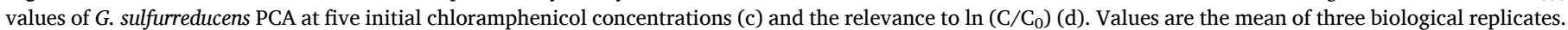
Error bars represent the SD. 
Table 1

Removal rate (\%), optical density $\mathrm{OD}_{600}$ and removal rate constant $\left(k_{\text {app }}\right)$ at different initial concentrations of chloramphenicol.

\begin{tabular}{|c|c|c|c|c|c|c|}
\hline \multirow[t]{2}{*}{ Concentration (mg/L) } & \multicolumn{3}{|l|}{$30{ }^{\circ} \mathrm{C}$} & \multicolumn{3}{|l|}{$37^{\circ} \mathrm{C}$} \\
\hline & Removal rate (\%) & $\mathrm{OD}_{600}$ & $k_{a p p}$ & Removal rate (\%) & $\mathrm{OD}_{600}$ & $k_{\text {app }}$ \\
\hline 5 & 100 & $0.249 \pm 0.029$ & 0.0397 & 100 & $0.401 \pm 0.009$ & 0.0658 \\
\hline 10 & $76.51 \pm 0.234$ & $0.169 \pm 0.014$ & 0.0305 & 100 & $0.362 \pm 0.010$ & 0.0498 \\
\hline 20 & $43.02 \pm 0.169$ & $0.059 \pm 0.007$ & 0.0144 & $85.28 \pm 4.28$ & $0.196 \pm 0.006$ & 0.0433 \\
\hline 30 & $28.01 \pm 0.289$ & $0.04 \pm 0.006$ & 0.0054 & $74.06 \pm 2.62$ & $0.121 \pm 0.001$ & 0.0136 \\
\hline 50 & $20.10 \pm 0.24$ & $0.03 \pm 0.006$ & 0.0043 & $59.93 \pm 0.22$ & $0.119 \pm 0.005$ & 0.0096 \\
\hline
\end{tabular}

Overall, results of chloramphenicol removal with G. sulfurreducens PCA alone at $30{ }^{\circ} \mathrm{C}$ show that the removal rate decreases with increasing chloramphenicol levels, and that removal is likely due to microbial processes, versus physicochemical adsorption. In the next section we tested the effect of temperature to try to improve the removal.

\subsection{Effect of temperature on chloramphenicol removal by electroactive bacteria}

The biodegradation rate of antibiotics should improve with temperature (Wen et al., 2010). Therefore we tested the effect of elevation from $30^{\circ} \mathrm{C}$ to $37^{\circ} \mathrm{C}$ on chloramphenicol removal. Results show that
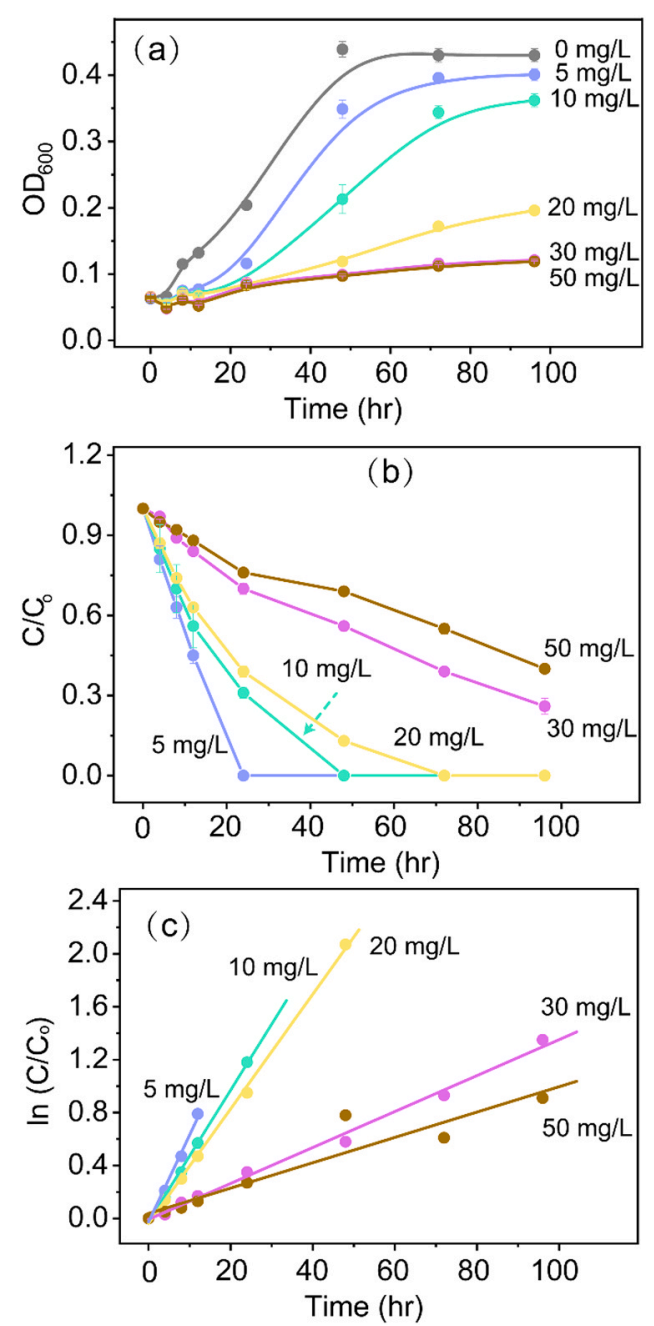

Fig. 2. Time course of the removal of chloramphenicol by $G$. sulfurreducens PCA at $37{ }^{\circ} \mathrm{C}$ with increasing biomass. The $\mathrm{OD}_{600}$ values of $G$. sulfurreducens PCA at five initial concentrations (a) and the degradation kinetics (b) and kinetic fitting (c). Values are the mean of three biological replicates. Error bars represent the SD. bacterial biomass measured by optical density is much higher at $37{ }^{\circ} \mathrm{C}$ than at $30^{\circ} \mathrm{C}$ (Figs. 1c and 2a, Table 1). Chloramphenicol was completely removed after a cultivation of $72 \mathrm{~h}$ when chloramphenicol concentration was less than $20 \mathrm{mg} / \mathrm{L}$ (Fig. 2b). Compared with $30^{\circ} \mathrm{C}$, the removal rates of $30 \mathrm{mg} / \mathrm{L}$ chloramphenicol (74.06\%) and $50 \mathrm{mg} / \mathrm{L}$ chloramphenicol (59.93\%) presented a twofold increase (Table 1). The values of $k_{\text {app }}$ of 5 and $10 \mathrm{mg} / \mathrm{L}$ chloramphenicol were 0.0658 and $0.0498 \mathrm{~h}^{-1}$, which were about 1.66 and 1.63 times compared to $30^{\circ} \mathrm{C}$. It indicated that low concentration of chloramphenicol $(<10 \mathrm{mg} / \mathrm{L})$ could be eliminated completely by a small amount of $G$. sulfurreducens PCA. While, more biomass was necessary for efficient removal along with the increasing of chloramphenicol contents. In the same vein, the removal rate is much higher at $37{ }^{\circ} \mathrm{C}$, yielding for example a threefold increase at $50 \mathrm{mg} / \mathrm{L}$, from about $20 \%$ removal at $30{ }^{\circ} \mathrm{C}$ to $60 \%$ removal at $37{ }^{\circ} \mathrm{C}$. Beside biomass, other biological factors, such as specific enzyme activities, might also been impacted with the increase of temperature. Hence, the promotion of chloramphenicol degradation could be the consequence of coaction of biomass and biological factors with a higher temperature, $37^{\circ} \mathrm{C}$.

\subsection{Electrical responses during chloramphenicol removal}

In experiment 3 we used cyclic voltametry and chronoamperometry to characterize the catalytic ability of $G$. sulfurreducens PCA to degrade chloramphenicol without exogenous organic carbon. This experiment was aimed at optimizing conditions of removal. Results show a weak reduction peak, at $10.1 \mathrm{nA} / \mathrm{cm}^{2}$, in the control group at $-0.6 \mathrm{~V}$ (Fig. 3a), which is the chloramphenicol reduction potential as previous reported (Alizadeh et al., 2012; Mao et al., 2018b). Therefore chloramphenicol probably undergoes weak reductive degradation with the electric field. In the presence of $G$. sulfurreducens PCA, the peak current density of $27.5 \mathrm{nA} / \mathrm{cm}^{2}$ was 2.3-fold higher compared to the control group, which implies that $G$. sulfurreducens PCA directly induced chloramphenicol reduction using the electrode as electron donor. This enhancement of peak current by electroactive microorganisms and degradation rate is in line with previous reports (Liang et al., 2013; Xu et al., 2019). The catalytic activity of $G$. sulfurreducens PCA was further investigated by chronoamperometry at a fixed potential of $-0.6 \mathrm{~V}$ (Fig. 3b). With each chloramphenicol addition, some small reduction peaks appeared, suggesting that weak abiotic degradation of chloramphenicol existed. Results show almost no variation without bacteria, and the very small peaks are probably due to abiotic degradation, as suggested also by a weaker redox peak in cyclic voltametry. By contrast, the current density increased sharply with bacteria with the involvement of G. sulfurreducens PCA, reaching $12.38 \mathrm{nA} / \mathrm{cm}^{2}$, which is three times that of the control, of $4.03 \mathrm{nA} / \mathrm{cm}^{2}$. Comprehensive results verified that chloramphenicol degradation occurred directly in the electric field and was further catalyzed by $G$. sulfurreducens PCA.

Detoxification of chloramphenicol using a biocathode with an external power source has been shown in various media (Cotillas et al., 2018; Guo et al., 2018; Liang et al., 2013). Although it was demonstrated that electrochemical reduction decreases the antibacterial activity of chloramphenicol (Kong et al., 2015), the critical voltage for chloramphenicol degradation is unknown. Therefore we tested cathode potentials of $-0.4,-0.5,-0.6$ and $-0.1 \mathrm{~V}$ to provide electrons in experiment 

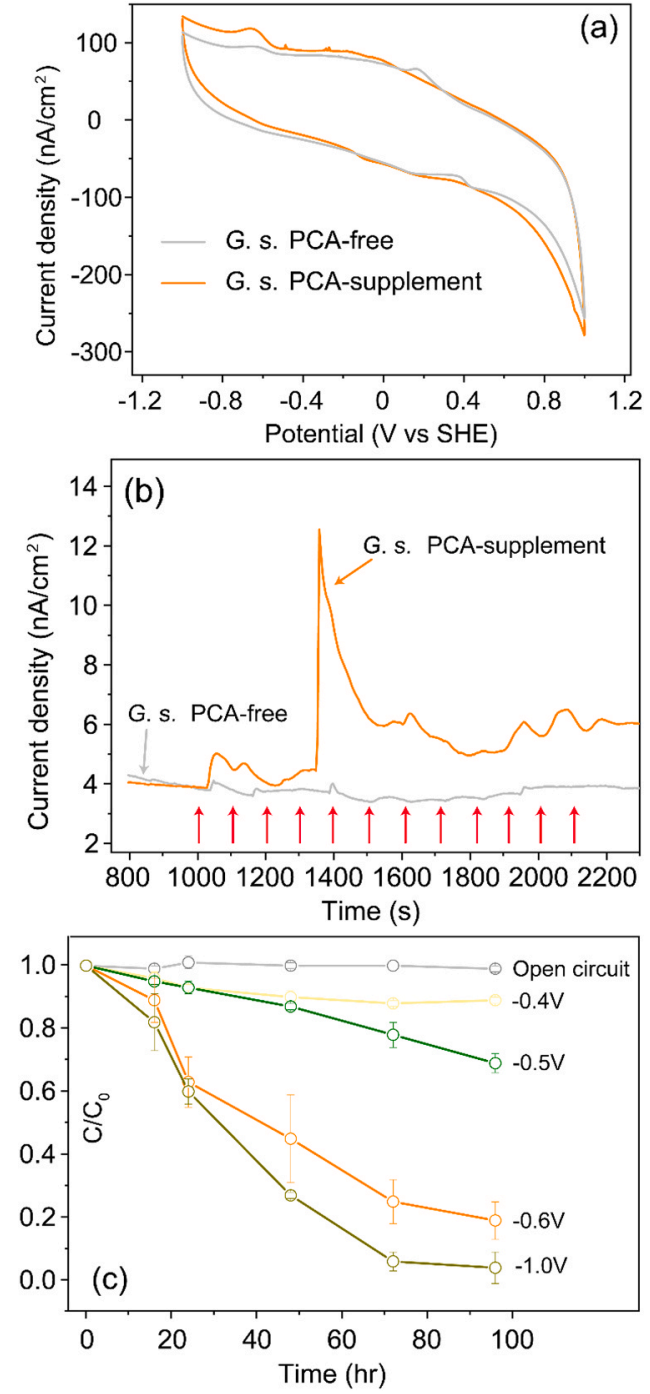

Fig. 3. The electrical signal during chloramphenicol degradation. Cyclic voltammograms (a), chronoamperometry (b) and external electric field (c) were used. The red arrows in (b) represented the intermittent addition of chloramphenicol. Values are the mean of three biological replicates. Error bars represent the SD.(For interpretation of the references to colour in this figure legend, the reader is referred to the web version of this article.)

4. Results show that removal increases from $11.11 \%$ at $-0.4 \mathrm{~V}$ to $81.41 \%$ at $-1.0 \mathrm{~V}$ (Fig. 3c). In details, about $11.11 \%$ of chloramphenicol was reduced at $-0.4 \mathrm{~V}$. In contrast, there was no decrease of chloramphenicol content under the condition of open circuit. As the potential was lowered to $-0.5 \mathrm{~V}$, the removal rate of chloramphenicol was increased to about $31.06 \%$. The decrease of the potential from $-0.5 \mathrm{~V}$ to $-0.6 \mathrm{~V}$ significantly accelerated the removal rate of chloramphenicol, from $31.06 \%$ to $81.41 \%$, an increase of about 2.62 times without bacteria. Robust decrease of the potential to $-1.0 \mathrm{~V}$ further increased the degradation rate of chloramphenicol, but the benefit was slight. Therefore, the optimum potential for chloramphenicol degradation should be between $-0.5 \mathrm{~V}$ and $-0.6 \mathrm{~V}$.

Overall, our results show the effective catalysis of chloramphenicol degradation by $G$. sulfurreducens PCA in an electric field, and that degradation should be critical between $-0.5 \mathrm{~V}$ and $-0.6 \mathrm{~V}$. The next section explores the synergy of electroactive bacteria and an electrical field.

\subsection{Synergistic operation of biocatalysis and electric field for chloramphenicol removal}

Since we found a sharp drop of removal efficiency from $-0.6 \mathrm{~V}$ to $-0.5 \mathrm{~V}$ in the electric field alone, in experiment 5 we added G. sulfurreducens PCA into the system to test a possible improvement of degradation efficiency (Fig. 4). At $-0.6 \mathrm{~V}$, the addition of G. sulfurreducens PCA slightly improved the degradation ability (Fig. 4a). In sharp contrast, the degradation is highly enhanced at $-0.5 \mathrm{~V}$ $(p<0.05)$. The corresponding $k_{\text {app }}$ is $0.0157 \mathrm{~h}^{-1}$, which is close to the efficiency of the cathode potential at $-0.6 \mathrm{~V}, 0.0184 \mathrm{~h}^{-1}$, and more than four-fold that of the control group, of $0.0038 \mathrm{~h}^{-1}$. These results demonstrate the synergy of electroactive bacteria and the electrical field for chloramphenicol degradation. Previous work showed that $17 \alpha$ ethinylestradiol removal was improved by coupling electrochemical methods with anaerobic bacteria (He et al., 2017), yet critical potentials are still unknown which is important for energy costs. G. sulfurreducens PCA could make up for the required potential difference, namely it was feasible to achieve the same degradation efficiency even at a higher potential (from -0.6 to $-0.5 \mathrm{~V}$ ). Our results thus imply on the applied side that combining electroactive bacteria and an electric field requires higher voltage, and thus less energy.

Acetate is an important substrate and electron donor for Geobacter spp (Caccavo et al., 1994; Xiao et al., 2018, 2019a). Therefore, we investigated the effect of adding sodium acetate to enhance the exoelectrogenic degradation of chloramphenicol. Results show that adding sodium acetate stimulated the capability of $G$. sulfurreducens PCA with a high removal rate at both -0.5 and $-0.6 \mathrm{~V}$ (Fig. 4b, Table 2). A such improvement is in agreement with the fact that Geobacter-affiliated phylotypes accounted to more than $40 \%$ of total bacteria following acetate feeding in microbial fuel cells (Zhang et al., 2014). Our data show that chloramphenicol degradation follows a first-order reaction kinetics
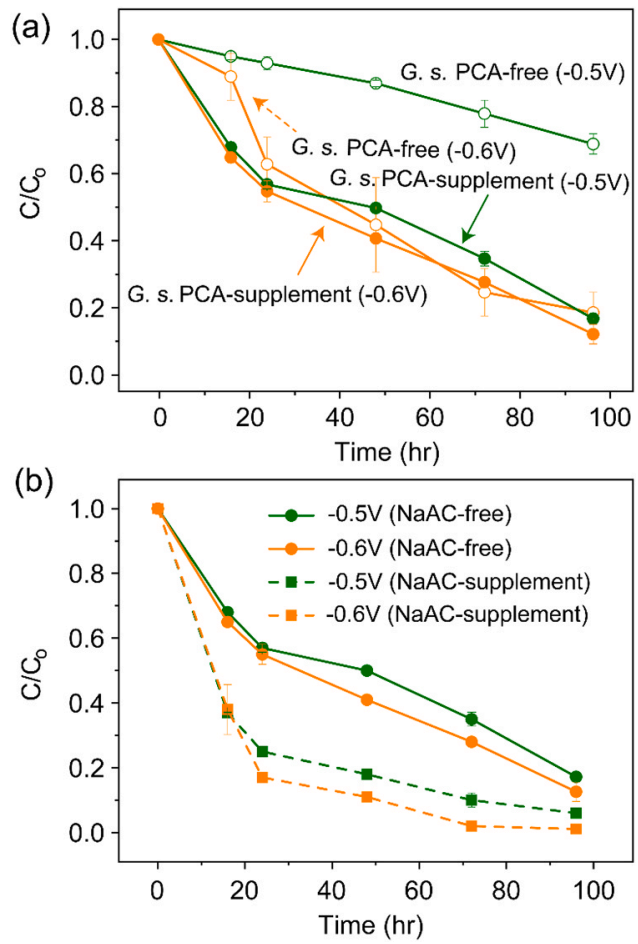

Fig. 4. Time course of removal of chloramphenicol under different cathode potentials with and without G. sulfurreducens PCA. Chloramphenicol degradation under potentials of -0.5 and $-0.6 \mathrm{~V}$ with and without $G$. sulfurreducens PCA (a). The strengthening of chloramphenicol degradation by $G$. sulfurreducens PCA with extra acetate addition. Values are the mean of three biological replicates (b). Error bars represent the SD. 
Table 2

Removal rate and removal rate constant $\left(k_{\text {app }}\right)$ under electric field. (chloramphenicol concentration was $30 \mathrm{mg} / \mathrm{L}$ ).

\begin{tabular}{llllll}
\hline $\begin{array}{l}\text { Cathode } \\
\text { alone }\end{array}$ & $\begin{array}{l}\text { Removal rate } \\
(100 \%)\end{array}$ & $k_{\text {app }}$ & $\begin{array}{l}\text { Cathode- } \\
\text { G.s. PCA }\end{array}$ & $\begin{array}{l}\text { Removal rate } \\
(100 \%)\end{array}$ & $k_{\text {app }}$ \\
\hline$-0.4 \mathrm{~V}$ & $10.62 \pm 0.12$ & 0.0012 & $-0.5 \mathrm{~V}$ & $82.77 \pm 0.75$ & 0.0157 \\
$-0.5 \mathrm{~V}$ & $40.46 \pm 1.32$ & 0.0038 & $-0.6 \mathrm{~V}$ & $87.44 \pm 2.88$ & 0.0285 \\
$-0.6 \mathrm{~V}$ & $78.64 \pm 2.13$ & 0.0184 & $-0.5 \mathrm{~V}-$ & $94.40 \pm 1.57$ & 0.0201 \\
& & & NaAC & & \\
$-1.0 \mathrm{~V}$ & $97.11 \pm 1.94$ & 0.0373 & $\begin{array}{l}-0.6 \mathrm{~V}- \\
\text { NaAC }\end{array}$ & $98.95 \pm 1.49$ & 0.0417 \\
\hline
\end{tabular}

with a removal efficiency reaching $98.95 \%$ at $-0.6 \mathrm{~V}$ by combining biocatalysis and electric field, which is $11.51 \%$ higher than that of the negative group without sodium acetate $(p<0.05)$. Moreover, the presence of electroactive bacteria raised $k_{\text {app }} 1.34$-fold versus the control without bacteria. Noteworthy, the degradation rate at $-0.5 \mathrm{~V}$ was even higher with bacteria than that of the electric field alone at $-0.6 \mathrm{~V}$, with rate constants of $0.0201 \mathrm{~h}^{-1}$ versus $0.0184 \mathrm{~h}^{-1}$, and removal of $94.40 \%$ versus $81.81 \%$, respectively $(p<0.05)$. Overall our findings demonstrate the synergy of electroactive bacteria and an electrical field to remove chloramphenicol, and that addition of sodium acetate further increases the degradation efficiency.

\subsection{Analysis of degradation products}

Chloramphenicol metabolites were analysed after degradation using both G. sulfurreducens PCA and an electric field in experiment 6 (Fig. 5). Chloramphenicol, which show typical $\mathrm{m} / z$ ratios at 321,323 and 325 by HPLC-MS/MS (Xu et al., 2019), was not detected at the end of our experiments, suggesting complete removal. We detected small amounts of an aromatic amine $\left(\mathrm{AMCl}_{2}\right)$ at $\mathrm{m} / z 295$ (Fig. 5a), suggesting that nitro groups of chloramphenicol was reduced to amino substituents. This is in line with nitro reduction and dechlorination observed previously for chloramphenicol (Kong et al., 2015, Lin et al., 2019; Yang et al., 2020b). Noteworthy, it is reported that AMCl2 induces $1 / 500$ of the toxicity of the corresponding nitroaromatic precursor (Donlon et al., 1995; Xu et al., 2019). In our experiment, AMCl2 was probably further dechlorinated to produce inactive antibacterial products AMCl at the $m / z$ of 279 $\left[\mathrm{M}+\mathrm{Na}^{+}\right]$(Fig. 5a). This suggests that combining electroactive bacteria and an electric field has the potential to markedly reduce the biotoxicity of some antibiotics in the environments.

In brief, the degradation process of chloramphenicol by synergistic operation of biocatalysis and electric field is proposed (Fig. 5b). Chloramphenicol was firstly converted to $\mathrm{AMCl} 2$, i.e. the nitro group of chloramphenicol was replaced by amino group. Then, $\mathrm{AMCl} 2$ was translated to $\mathrm{AMCl}$ by dechlorination. These findings showed that cathode served an electron donor to promote effective chloramphenicol reduction. Under abiotic cathode condition, electrons directly reduce chloramphenicol to finish the nitro reduction or dechlorination process. By comparing the degradation progress of chloramphenicol under electric field alone at $-0.6 \mathrm{~V}$ (Experiment 4, Fig. S1), degradation products were similar with treatments in the presence of G. sulfurreducens PCA but lacking sodium acetate (Fig. 5a). After augmentation of $G$. sulfurreducens PCA by providing extra sodium acetate, the degradation products did not show significant difference (Fig. 5a and Fig. S2), suggesting that biocatalysis and abiotic reduction may follow the similar route for chloramphenicol degradation in this study (Fig. 5b). There are mainly two strategies for the degradation process: (1) G. sulfurreducens PCA could act as biocatalyst to realize nitro reduction or dechlorination reaction; (2) G. sulfurreducens PCA, as typical electroactive microorganism, could facilitate electron flow from cathode to chloramphenicol.
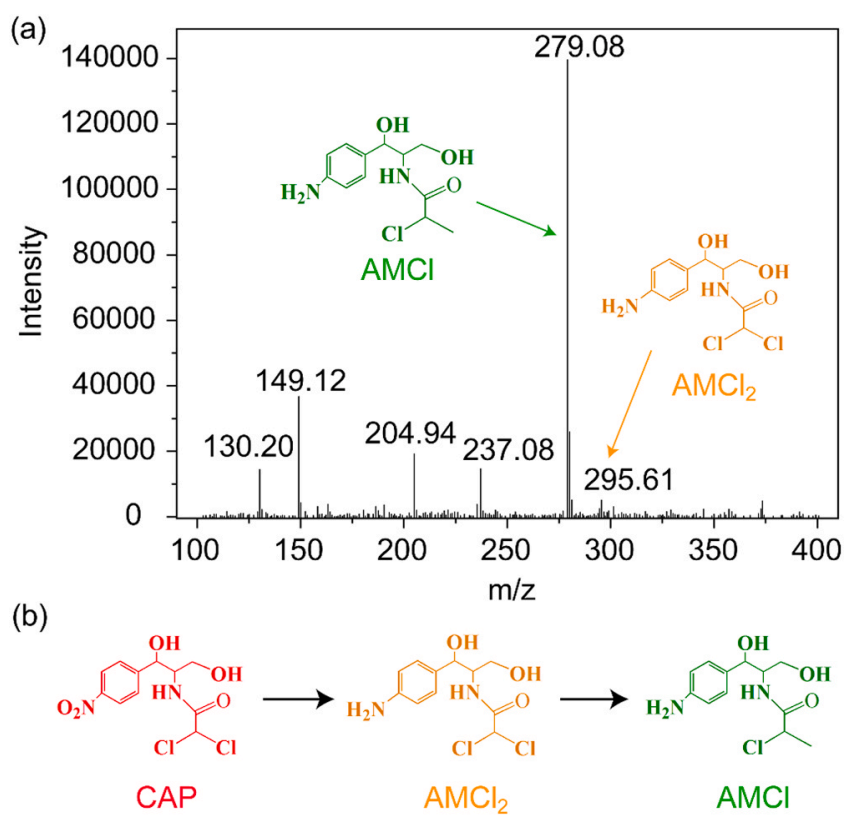

Fig. 5. The potential reduction products of chloramphenicol (a) and degradation pathway (b).

\section{Conclusion}

Chloramphenicol, a recalcitrant endocrine-disrupting contaminant, was efficiently removed by coupling $G$. sulfurreducens PCA with electric field. An obvious inhibitory effect on the dechlorination activity and growth of $G$. sulfurreducens PCA appeared when the dosages exceeded $20 \mathrm{mg} / \mathrm{L}$. Individual G. sulfurreducens PCA demonstrated relatively poor removal capability at $30^{\circ} \mathrm{C}$, such as $20 \%$ at $50 \mathrm{mg} / 1$. More effective removal was achieved with the increase of temperature to $37^{\circ} \mathrm{C}$ with the value of about $60 \%$ at $50 \mathrm{mg} / \mathrm{l}$. This study showed that single electrochemical method was with the capability of catalyzing chloramphenicol reduction, which could be impacted greatly by cathode potential. Notably, synergistic operation of biocatalysis by G. sulfurreducens PCA and electric field maximized chloramphenicol removal efficiency. The apparent rate constant at $-0.5 \mathrm{~V}$ was more than fourfold improvement with the addition of G. sulfurreducens PCA. Very interestingly, biocatalysis compensated or even stimulated the more robust chloramphenicol removal at a higher potential (from -0.6 to $-0.5 \mathrm{~V}$ ). The work proposes a feasible strategy for pollutant poisoning treatment by the synergistic operation of electroactive microorganisms and electric field.

\section{CRediT authorship contribution statement}

F.L., L.X. and J.L. designed the research. L.X., J.L., Z.L. and Q.W. performed the experiments. L.X., J.L. E. L. and F.L. analyzed the data. L. X., J.L., E. L. and F.L. wrote and revised the manuscript.

\section{Declaration of Competing Interest}

The authors declare that they have no known competing financial interests or personal relationships that could have appeared to influence the work reported in this paper.

\section{Acknowledgement}

This research was financially supported by the Strategic Priority Research Program of the Chinese Academy of Sciences (no. XDA22050301), the National Natural Science Foundation of China (no. 42077025, U20A20109), Youth Innovation Promotion Association, 
Chinese Academy of Sciences and the GDAS' Project of Science and Technology Development (2019GDASYL-0102003, 2020B1111530002, 2019QN01L735). We appreciate Mr. Yu Hang for the suggestions on data analysis. The editor and reviewers have made important contributions to the quality improvement of this paper.

\section{Appendix A. Supporting information}

Supplementary data associated with this article can be found in the online version at doi:10.1016/j.jhazmat.2020.124977.

\section{References}

Alizadeh, T., Ganjali, M., Zare, M., Norouzi, P., 2012. Selective determination of chloramphenicol at trace level in milk samples by the electrode modified with molecularly imprinted polymer. Food Chem. 130, 1108-1114.

Aulenta, F., Reale, P., Canosa, A., Rossetti, S., Panero, S., Majone, M., 2010. Characterization of an electro-active biocathode capable of dechlorinating trichloroethene and cis-dichloroethene to ethene. Biosens. Bioelectron. 25, 1796-1802.

Aydin, S., Ince, B., Ince, O., 2015. Development of antibiotic resistance genes in microbial communities during long-term operation of anaerobic reactors in the treatment of pharmaceutical wastewater. Water Res. 83, 337-344.

Biancullo, F., Moreira, N., Ribeiro, A., Manaia, C., Faria, J., Nunes, O., Castro-Silva, S., Silva, A., 2019. Heterogeneous photocatalysis using UVA-LEDs for the removal of antibiotics and antibiotic resistant bacteria from urban wastewater treatment plant effluents. Chem. Eng. J. 367, 304-313.

Boeckx, R., Brett, E., 2019. A bioluminescence micromethod for measuring chloramphenicol in serum. Clin. Chem. 6, 819-822.

Boyd, S., Shelton, D., Berry, D., Tiedje, J., 1983. Anaerobic biodegradation of phenolic compounds in digested sludge. Appl. Environ. Microbiol. 46, 50-54.

Caccavo, F., Lonergan, D., Lovley, D., Davis, M., Stolz, J., McInerney, M., 1994. Geobacter sulfurreducens sp. nov., a hydrogen-and acetate-oxidizing dissimilatory metalreducing microorganism. Appl. Environ. Microbiol. 60, 3752-3759.

Chen, M., Zhou, X., Liu, X., Zeng, R.J., Zhou, S., 2018. Facilitated extracellular electron transfer of Geobacter sulfurreducens biofilm with in situ formed gold nanoparticles. Biosens. Bioelectron. 108, 20-26.

Coppi, M., Leang, C., Sandler, S., Lovley, D., 2001. Development of a genetic system for Geobacter sulfurreducens. Appl. Environ. Microbiol. 67, 3180-3187.

Cotillas, S., Lacasa, E., Sáez, C., Cañizares, P., Rodrigo, M., 2018. Electrolytic and electroirradiated technologies for the removal of chloramphenicol in synthetic urine with diamond anodes. Water Res. 128, 383-392.

Cycon, M., Mrozik, A., Piotrowska-Seget, Z., 2019. Antibiotics in the soil environmentdegradation and their impact on microbial activity and diversity. Front. Microbiol. 10,338 .

Deng, D., Deng, F., Tang, B., Zhang, J., Liu, J., 2017. Electrocatalytic reduction of lowconcentration thiamphenicol and florfenicol in wastewater with multi-walled carbon nanotubes modified electrode. J. Hazard. Mater. 332, 168-175.

Dong, H., Qiang, Z., Hu, J., Qu, J., 2017. Degradation of chloramphenicol by UV/ chlorine treatment: kinetics, mechanism and enhanced formation of halonitromethanes. Water Res. 121, 178-185.

Donlon, B., Razo-Flores, E., Field, J., Lettinga, G., 1995. Toxicity of N-substituted aromatics to acetoclastic methanogenic activity in granular sludge. Appl. Environ. Microbiol. 61, 3889-3893.

Dou, M., Wang, J., Gao, B., Xu, C., Yang, F., 2020. Photocatalytic difference of amoxicillin and cefotaxime under visible light by mesoporous $\mathrm{g}-\mathrm{C}_{3} \mathrm{~N}_{4}$ : mechanism, degradation pathway and DFT calculation. Chem. Eng. J. 383, 123134.

Garcia-Segura, S., Cavalcanti, E., Brillas, E., 2014. Mineralization of the antibiotic chloramphenicol by solar photoelectro-Fenton: from stirred tank reactor to solar prepilot plant. Appl. Catal. B Environ. 144, 588-598.

Guo, H., Jiang, N., Wang, H., Lu, N., Shang, K., Li, J., Wu, Y., 2019. Degradation of antibiotic chloramphenicol in water by pulsed discharge plasma combined with $\mathrm{TiO}_{2} / \mathrm{WO}_{3}$ composites: mechanism and degradation pathway. J. Hazard. Mater. 371, 666-676.

He, H., Huang, B., Fu, G., Du, Y., Xiong, D., Lai, C., Pan, X., 2017. Coupling electrochemical and biological methods for $17 \alpha$-ethinylestradiol removal from water by different microorganisms. J. Hazard. Mater. 340, 120-129.

Hong, X., Zhao, Y., Zhuang, R., Liu, J., Guo, G., Chen, J., Yao, Y., 2020. Bioremediation of tetracycline antibiotics-contaminated soil by bioaugmentation. RSC Adv. 10 (55), 33086-33102.

Huang, S., Tang, J., Liu, X., Dong, G., Zhou, S., 2019. Fast light-driven biodecolorization by a Geobacter sulfurreducens-CdS biohybrid. ACS Sustain. Chem. Eng. 7, 15427-15433.

Karaolia, P., Michael-Kordatou, I., Hapeshi, E., Drosou, C., Bertakis, Y., Christofilos, D., Armatas, G., Sygellou, L., Schwartz, T., Xekoukoulotakis, N., 2018. Removal of antibiotics, antibiotic-resistant bacteria and their associated genes by graphenebased $\mathrm{TiO}_{2}$ composite photocatalysts under solar radiation in urban wastewaters. Appl. Catal. B Environ. 224, 810-824.

Kong, D., Liang, B., Yun, H., Cheng, H., Ma, J., Cui, M., Wang, A., Ren, N., 2015. Cathodic degradation of antibiotics: characterization and pathway analysis. Water Res. 72, 281-292.
Kunapuli, U., Jahn, M., Lueders, T., Geyer, R., Heipieper, H., Meckenstock, R., 2010. Desulfitobacterium aromaticivorans sp. nov. and Geobacter toluenoxydans sp. nov., iron-reducing bacteria capable of anaerobic degradation of monoaromatic hydrocarbons. Int. J. Syst. Evol. Micrbiol. 60, 686-695.

Li, J., Xiao, L., Zheng, S., Zhang, Y., Luo, M., Tong, C., Xu, H., Tan, Y., Liu, J., Wang, O., 2018. A new insight into the strategy for methane production affected by conductive carbon cloth in wetland soil: beneficial to acetoclastic methanogenesis instead of $\mathrm{CO}_{2}$ reduction. Sci. Total Environ. 643, 1024-1030.

Li, Z., Cheng, R., Chen, F., Lin, X., Yao, X., Liang, B., Huang, C., Sun, K., Wang, A., 2020. Selective stress of antibiotics on microbial denitrification: inhibitory effects, dynamics of microbial community structure and function. J. Hazard. Mater. 405, 124366.

Liang, B., Cheng, H., Kong, D., Gao, S., Sun, F., Cui, D., Kong, F., Zhou, A., Liu, W., Ren, N., 2013. Accelerated reduction of chlorinated nitroaromatic antibiotic chloramphenicol by biocathode. Environ. Sci. Technol. 47, 5353-5361.

Lin, X., Li, Z., Liang, B., Zhai, H., Cai, W., Nan, J., Wang, A., 2019. Accelerated microbial reductive dechlorination of 2,4,6-trichlorophenol by weak electrical stimulation. Water Res 162, 236-245.

Liu, J., Zhong, S., Song, Y., Wang, B., Zhang, F., 2018. Degradation of tetracycline hydrochloride by electro-activated persulfate oxidation. J. Electro Chem. 809, 74-79.

Liu, Y., Zhang, F., Li, J., Li, D., Liu, D., 2017a. Exclusive extracellular bioreduction of methyl orange by azo reductase-free Geobacter sulfurreducens. Environ. Sci. Technol. $51,8616-8623$.

Liu, Z., Zhu, M., Zhao, L., Deng, C., Ma, J., Wang, Z., Liu, H., Wang, H., 2017b. Aqueous tetracycline degradation by coal-based carbon electrocatalytic filtration membrane: effect of nano antimony-doped tin dioxide coating. Chem. Eng. J. 314, 59-68.

Mao, F., Liu, X., Wu, K., Zhou, C., Si, Y., 2018a. Biodegradation of sulfonamides by Shewanella oneidensis MR-1 and Shewanella sp. strain MR-4. Biodegradation 29, 129-140.

Mao, Y., Guo, L., Ning, X., Li, J., Zheng, J., 2018b. The signal amplification in electrochemical detection of chloramphenicol using sulfonated polyaniline-chitosan composite as redox capacitor. Electroanal 30, 2085-2093.

Palma, E., Daghio, M., Tofalos, A., Franzetti, A., Viggi, C., Fazi, S., Papini, M., Aulenta, F., 2018. Anaerobic electrogenic oxidation of toluene in a continuous-flow bioelectrochemical reactor: process performance, microbial community analysis, and biodegradation pathways. Environ. Sci. Water Res. 4, 2136-2145.

Pan, M., Chu, L., 2016. Adsorption and degradation of five selected antibiotics in agricultural soil. Sci. Total Environ. 545, 48-56.

Peng, X., Cao, J., Xie, B., Duan, M., Zhao, J., 2020. Evaluation of degradation behavior over tetracycline hydrochloride by microbial electrochemical technology: performance, kinetics, and microbial communities. Ecotoxicol. Environ. Saf. 188, 109869.

Schymanski, E., Jeon, J., Gulde, R., Fenner, K., Ruff, M., Singer, H., Hollender, J., 2014. Identifying small molecules via high resolution mass spectrometry: communicating confidence. Environ. Sci. Technol. 48 (4), 2097-2098.

Sharma, M., Nandy, A., Taylor, N., Venkatesan, S.V., Kollath, V.O., Karan, K., Thangadurai, V., Tsesmetzis, N., Gieg, L.M., 2020. Bioelectrochemical remediation of phenanthrene in a microbial fuel cell using an anaerobic consortium enriched from a hydrocarbon-contaminated site. J. Hazard. Mater. 389, 121845.

Wang, J., Zhuan, R., 2020. Degradation of antibiotics by advanced oxidation processes: an overview. Sci. Total Environ. 701, 135023.

Wang, L., Liu, Y., Wang, C., Zhao, X., Mahadeva, G., Wu, Y., Ma, J., Zhao, F., 2018. Anoxic biodegradation of triclosan and the removal of its antimicrobial effect in microbial fuel cells. J. Hazard. Mater. 344, 669-678.

Wei, Z., Liu, J., Shangguan, W., 2020. A review on photocatalysis in antibiotic wastewater: pollutant degradation and hydrogen production. Chin. J. Catal. 41, $1440-1450$.

Wen, X., Jia, Y., Li, J., 2010. Enzymatic degradation of tetracycline and oxytetracycline by crude manganese peroxidase prepared from Phanerochaete chrysosporium. J. Hazard. Mater. 177, 924-928.

Xiao, L., Liu, F., Liu, J., Li, J., Zhang, Y., Yu, J., Wang, O., 2018. Nano- $\mathrm{Fe}_{3} \mathrm{O}_{4}$ particles accelerating electromethanogenesis on an hour-long timescale in wetland soil. Environ. Sci. Nano 5, 436-445.

Xiao, L., Liu, F., Xu, H., Feng, D., Liu, J., Han, G., 2019a. Biochar promotes methane production at high acetate concentrations in anaerobic soils. Environ. Chem. Lett. $17,1347-1352$.

Xiao, L., Sun, R., Zhang, P., Zheng, S., Tan, Y., Li, J., Zhang, Y., Liu, F., 2019b. Simultaneous intensification of direct acetate cleavage and $\mathrm{CO}_{2}$ reduction to generate methane by bioaugmentation and increased electron transfer. Chem. Eng. J. 378, 122229 .

Xiao, L., Wei, W., Luo, M., Xu, H., Feng, D., Yu, J., Huang, J., Liu, F., 2019c. A potential contribution of a Fe(III)-rich red clay horizon to methane release: Biogenetic magnetite-mediated methanogenesis. Catena 181, 104081.

Xiao, L., Zheng, S., Lichtfouse, E., Luo, M., Tan, Y., Liu, F., 2020a. Carbon nanotubes accelerate acetoclastic methanogenesis: from pure cultures to anaerobic soils. Soil Biol. Biochem. 150, 107938.

Xiao, L., Liu, F., Lichtfouse, E., Zhang, P., Feng, D., Li, F., 2020b. Methane production by acetate dismutation stimulated by Shewanella oneidensis and carbon materials: an alternative to classical $\mathrm{CO}_{2}$ reduction. Chem. Eng. J. 389, 124469.

Xiao, L., Wang, Y., Lichtfouse, E., Li, Z., Kumar, S., Liu, J., Feng, D., Yang, Q., Liu, F., 2021. Effect of antibiotics on the microbial efficiency of anaerobic digestion of wastewater: a review. Front. Microbiol. https://doi.org/10.3389/ fmicb.2020.611613. 
Xu, H., Xiao, L., Zheng, S., Zhang, Y., Li, J., Liu, F., 2019. Reductive degradation of chloramphenicol by Geobacter metallireducens. Sci. China Technol. Sci. 62, 1688-1694.

Xu, J., Liu, X., Cao, Z., Bai, W., Shi, Q., Yang, Y., 2020. Fast degradation, large capacity, and high electron efficiency of chloramphenicol removal by different carbonsupported nanoscale zerovalent iron. J. Hazard. Mater. 384, 121253.

Yang, F., Jian, H., Wang, C., Wang, Y., Li, E., Sun, H., 2020a. Effects of biochar on biodegradation of sulfamethoxazole and chloramphenicol by Pseudomonas stutzeri and Shewanella putrefaciens: microbial growth, fatty acids, and the expression quantity of genes. J. Hazard. Mater., 124311

Yang, G., Huang, L., You, L., Zhuang, L., Zhou, S., 2017. Electrochemical and spectroscopic insights into the mechanisms of bidirectional microbe-electrode electron transfer in Geobacter soli biofilms. Electrochem. Commun. 77, 93-97.

Yang, K., Ji, M., Liang, B., Zhao, Y., Zhai, S., Ma, Z., Yang, Z., 2020b. Bioelectrochemical degradation of monoaromatic compounds: current advances and challenges. J. Hazard. Mater. 398, 122892.

Yin, R., Guo, W., Wang, H., Du, J., Zhou, X., Wu, Q., Zheng, H., Chang, J., Ren, N., 2018. Selective degradation of sulfonamide antibiotics by peroxymonosulfate alone: direct oxidation and nonradical mechanisms. Chem. Eng. J. 334, 2539-2546.
Yu, L., Yuan, Y., Tang, J., Wang, Y., Zhou, S., 2015. Biochar as an electron shuttle for reductive dechlorination of pentachlorophenol by Geobacter sulfurreducens. Sci. Rep. $5,16221$.

Zhang, H., Chen, X., Braithwaite, D., He, Z., 2014. Phylogenetic and metagenomic analyses of substrate-dependent bacterial temporal dynamics in microbial fuel cells. Plos One 9 (9), e107460.

Zhang, J., Zhao, R., Cao, L., Lei, Y., Liu, J., Feng, J., Fu, W., Li, X., Li, B., 2020. Highefficiency biodegradation of chloramphenicol by enriched bacterial consortia: kinetics study and bacterial community characterization. J. Hazard. Mater. 384 121344.

Zhang, T., Tremblay, P., Chaurasia, A., Smith, J., Lovley, D., 2013. Anaerobic benzene oxidation via phenol in Geobacter metallireducens. Appl. Environ. Microbiol. 79, 7800-7806.

Zhao, H., Xue, L., Zhen, C., Yi, Z., Shi, X., Yi, Y., Zhou, J., Jiang, X., 2016. Adsorption behavior and mechanism of chloramphenicols, sulfonamides, and non-antibiotic pharmaceuticals on multi-walled carbon nanotubes. J. Hazard. Mater. 310, 235-245.

Zhao, X., Chen, Z., Wang, X., Li, J., Shen, J., Xu, H., 2015. Remediation of harmaceuticals and personal care products using an aerobic granular sludge sequencing bioreactor and microbial community profiling using Solexa sequencing technology analysis. Bioresour. Technol. 179, 104-112. 